\title{
A TRADUÇÃO COMO ESTRATÉGIA PARA O ENSINO INTEGRADO DE LÍNGUA ESPANHOLA E LITERATURA BRASILEIRA
}

\author{
TRANSLATION AS A STRATEGY FOR INTEGRATED SPANISH LANGUAGE AND BRAZILIAN \\ LITERATURE
}

\author{
Liliana Patricia Marlés Valencia ${ }^{1}$, Luciano de Jesus Gonçalves ${ }^{2}$ \\ 1 Universidade de São Paulo (USP), São Paulo, SP, Brasil \\ lilianamarlesvalencia@gmail.com \\ 2 Instituto Federal de Educação, Ciência e Tecnologia do Tocantins (IFTO), Colinas do Tocantins, TO, \\ Brasil \\ ljg@usp.br
}

Recebido em 13 ago. 2018

Aceito em 21 ago. 2018

Resumo: A literatura, na sua complexidade linguística e, sobretudo, estético-artística, constitui-se num âmbito favorável para o aproveitamento de atividades que integrem as línguas e, assim, desenvolvam a habilidade comunicativa como um todo. Não surpreende que a tradução, prática que demanda o exercício duplo de compreensão e produção, esteja agora de volta às aulas como ferramenta para a aprendizagem. A contribuição desse artigo será, então, apontar um exercício de tradução como estratégia de ensino e aprendizagem de línguas e literaturas, portuguesa e espanhola, tendo como apoio a crônica "Feia demais", do escritor Nelson Rodrigues. Esse artigo volta-se, também, para o marco legal da proposta de Base Nacional Comum Curricular - Ensino Médio, homologado pela Portaria $n^{\circ} 1.570$, publicada no Diário Oficial da União de 21/12/2017, às vésperas de sua implementação oficial, documento que tem animado o debate educacional brasileiro, com vistas a situar a defesa de um ensino literatura diverso e plurilíngue. Ainda que tal proposta não vislumbre maiores recomendações para o ensino de língua espanhola no Ensino Médio, o que se configura como espécie de sequestro dessa segunda língua na nova base, aos docentes da área, o momento aponta para a necessidade de se discutir metodologias escolares e de se posicionar sobre tal legislação.

Palavras-chave: Base Nacional Comum Curricular. Currículo de Ensino Médio. Ensino de Literatura. Línguas Estrangeiras Modernas. Currículo. Nelson Rodrigues.

\begin{abstract}
The literature, given its linguistic and, above all, aesthetic-artistic complexity emerges as a suitable field to explore activities that contribute to languages integration, and so for, to develop the communicative skill as a whole. Not surprisingly, translation, a comprehension - production bound activity, is back into school practice as a tool for learning. The contribution of this text will be to suggest a translation exercise as a strategy for teaching and learning of Portuguese and Spanish languages and literatures, all this based upon "Feia demais", the story by Nelson Rodrigues. This article also turns to the legal framework proposal Base Nacional Comum Curricular- Ensino Médio, approved by the legal document $n^{\circ} 1.570$, published on Diário Oficial da União de 21/12/2017, days before its implementation, a document which has raised the Brazilian educational debate, with the aim of standing up for diverse and multilingual literature teaching. The fact that the proposal does not envisage any strong recommendations for Spanish language teaching in High School curriculum can be considered as an act of kidnapping this foreign language. The complexity of the historical moment demands from the teachers to discuss methodologies in order to take a position in the face of this legislation.
\end{abstract}

Keywords: National Common Curricular Basis. High School Curriculum. Literature teaching. Modern foreign languages. Syllabus. Nelson Rodrigues. 


\section{Introdução}

As práticas de linguagem oferecem oportunidades únicas para construir um tipo específico de conhecimento que possibilita se perceber como parte de um mundo multicultural, mas de um modo singular, ao mesmo tempo. Na construção dos significados coletivos, resultantes das práticas de linguagem, o sujeito amplia as maneiras de se relacionar com sua comunidade mais imediata e com outras, de diferenças mais marcadas. Ao se constituírem em ferramentas que fornecem recursos para expressar experiências estéticas, cognoscitivas ou corporais, entre outras, as linguagens podem ser, também, instrumentos capazes de gerar conflitos.

Depreende-se a necessidade de oferecer aos estudantes um contato profuso com questões da diversidade e da diferença, elementos valiosos e inerentes à sociedade, sem desconsiderar o conhecimento de mundo daquele que aprende. Como bem defendeu Paulo Freire (1989), cabe ao profissional da educação, mediador e condutor desse processo, a seleção e o tratamento desses materiais.

O caráter discursivo da língua origina a condição plural das situações que pode enfrentar um falante, mesmo dentro dessa sua "primeira língua". Daí a necessidade de atender à diversidade textual, à multiplicidade dos suportes e das linguagens, tendo sempre presentes as diversas esferas de uso que envolvem tanto a oralidade como a escrita. A capacidade crítica e criativa em relação à Língua Materna deve, de mesmo modo, acompanhar a aprendizagem de uma língua estrangeira.

É no âmbito da educação bilingue que Cummins $(1976,1984)$ tem desenvolvido as suas pesquisas. Embora o contexto aqui contemplado seja o de Ensino de Língua Estrangeira e não o de Educação Bilingue, essa proposta apoia-se nas descobertas de sua Teoria da interdependência. Ainda que existam críticas sobre tais teorizações, mantém-se como certa a hipótese a respeito de um nível básico de domínio comum a todas as línguas e à possibilidade de transferência de certas habilidades entre elas. Para tanto, precisa-se da instrução apropriada, não só para alertar sobre os momentos adequados para a aplicação e transferibilidade das destrezas, mas, também, e, principalmente, sobre as circunstâncias em que o componente cultural restringe aquela transferibilidade. 
Essa proposta se alinha às tentativas de se promover a consciência das relações entre identidade, língua e cultura, com vistas a estabelecer o diálogo pedagógico que marca tanto as diferenças quanto as semelhanças. No tocante a esta proposta, resulta fundamental a percepção da Língua Estrangeira Moderna como elemento para propiciar nos estudantes a desnaturalização das suas próprias culturas e línguas, de maneira que possa surgir uma reflexão sobre a Língua Portuguesa sob um novo olhar. No confronto com a diferença surge, de modo mais nítido, a nossa identidade. Nesse horizonte, a língua moderna em questão é a espanhola.

A esse respeito, aqui, a crônica literária "Feia demais", do escritor Nelson Rodrigues (1912-1980), serve de mote para a elaboração de sugestões que recaem sobre o ensino de literatura brasileira, mas não só. Uma versão em espanhol de um texto originariamente em português é tradada como suporte complementar para o trabalho integrado entre os componentes Língua Portuguesa e Língua Espanhola.

A proposta em si não se configura como um manual de ensino de literatura bilingue. Mais que uma receita definitiva de ensino, a realização aponta para a necessidade de o próprio professor da educação básica avaliar, discutir e ressemantizar os materiais didáticos que chegarão ao alvo final, motivo básico de sua atuação. No trabalho conjunto, as duas línguas são beneficiadas.

\section{O texto literário entre a fruição estética e as possibilidades curriculares}

A literatura, modo de construção e expressão da subjetividade, mesmo sem assumir esse compromisso, pode formar leitores capazes de refletir sobre a linguagem. Dentre os vários objetivos que podem ser alcançados com ela, apontamse: reconhecimento dos contextos de produção e circulação; desenvolvimento da participação oral e da escuta atenta; análise das diferenças de sentido entre palavras; a apreciação e valorização de autores de diferentes tradições e da variação linguística.

A seleção dos textos deverá corresponder, também, aos projetos em curso e levar em conta conhecimentos prévios. Só assim podem ser garantidas as condições para uma Aprendizagem Significativa, nos termos de David Ausubel 
(1963). É, justamente, nessa vocação integradora que nasce a proposta desse artigo, um trabalho conjunto entre os componentes de Língua Portuguesa e Língua Estrangeira, a espanhola, a partir do tratamento compartilhado de autores pertencentes tanto à Literatura Lusofalante como à Literatura Hispanofalante tanto nos textos "originais" quanto nas suas traduções e versões. No caso, trazemos a abordagem do texto literário, "Feia demais", extraído de A vida como ela é, do autor brasileiro Nelson Rodrigues e da sua tradução ao espanhol.

A escolha do escritor pernanbucano obedece a várias razões. Rodrigues forjou um lugar na literatura brasileira que dialoga entre o canônico e o popular. A variedade de gêneros textuais que abrange na sua obra é, em si, um apelo à multiplicidade das práticas da língua. Isso sem falar das suas incursões no terreno dos pseudônimos: estão aí Suzana Flag ou Myrna, como exemplos. Assim, a sua escrita, sempre polifônica, trouxe para a literatura as vozes da cidade. No teatro rodriguiano, o uso do português cotidiano tornou-se material trágico capaz de manter a solenidade da tragédia, mas vivificada por uma linguagem próxima da contemporaneidade dos leitores brasileiros.

Embora a produção cronística de Nelson Rodrigues seja profusa, seu lugar dentro do cânone brasileiro deve-se à sua obra dramática. É só nos últimos anos, quando o gênero da crônica tem conseguido uma relevância maior nos estudos literários, que os pesquisadores têm se debruçado com mais veemência sobre essa parte de sua produção. O livro Inteligência com dor (Fischer, 2009), que destaca entre as aproximações a cronística rodriguiana, analisa as crônicas como escrita ensaística.

O livro escolhido recolhe esses textos que temos decidido chamar ora de crônicas, ora de contos. Sendo que o jornal foi o contexto de produção em que essas narrações foram concebidas, elas têm sido chamadas também de crônicas. $A$ crônica tem na sua origem outras preocupações em relação à extensão e conteúdo (considerada um comentário leviano). Sendo que os textos respondem à estrutura reconhecida, de modo geral, como conto, eles são tratados tanto na edição pela Companhia das Letras, quanto na tradução ao espanhol pela editora Adriana Hidalgo, como contos. Essa transformação de um texto que se desloca entre os 
gêneros é uma chance para que o professor apresente as diferenças entre contexto de produção e contexto de recepção.

O acercamento a um autor brasileiro pode, claro, abrir as portas para se conhecer outras obras do universo literário hispanofalante com as quais se estabeleça um paradigma de literatura comparada. Se, no momento, essa proposta deixa de lado aquele percurso, é somente porque o interesse central é afirmar outro tipo de vínculo entre as duas línguas. O objetivo é, mais especificamente, diluir as fronteiras rígidas que levam ao pensamento de que a produção literária brasileira é um assunto exclusivo da aula de Língua Portuguesa. Conceitos pertinentes à instituição literária, tais como autoria, gênero literário, intertextualidade, só para dar alguns exemplos, podem ser melhor entendidos na sua complexidade e historicidade quando vistos à luz dos vasos comunicantes entre as diversas comunidades de recepção.

As pesquisas mostram que os aprendizes podem perceber as formas gramaticais com maior facilidade quando não precisam se preocupar com léxico (VAN PATTEN, 1996). Sendo assim, é possível e recomendado ao professor fazer uma primeira leitura do conto na sua tradução ao espanhol, estimulada por todos os conhecimentos prévios que têm sido introduzidos na aula de Língua Portuguesa.

Aqui vale a pena se deter na noção de Processamento do Input, elaborado inicialmente por Terrell (1991). O modelo, que tem sido alvo de pesquisas por parte do próprio Van Patten (1996, 2002), entre outros, concentra-se no processo de recebimento do input. Em decorrência desses estudos, tem sido demonstrado que os estudantes não conseguem prestar atenção à forma e ao significado de maneira simultânea. Logo, atenuadas as dificuldades lexicais e da compreensão geral do argumento, os alunos podem dirigir sua atenção a aspectos gramaticais de outra ordem.

Vários são os princípios a se levar em conta nas atividades de processamento do input, que tanto pode ser oral quanto escrito. Entre as propostas de Teresa Cadierno (2010), duas são de particular interesse para a prática aqui sugerida: usar atividades que não consistam em exercícios mecânicos e fazer com que os estudantes não sejam apenas receptores passivos, quer dizer, levar os alunos a aplicar esse input em alguma tarefa. 
O objetivo é convidar os escolares à reflexão sobre aspectos como as estruturas de ordem sintática, o uso dos signos de pontuação, os chamados "falsos amigos" ou falsos cognatos, entre o espanhol e o português. Num primeiro momento, o propósito é fornecer input que seja compreensível para os estudantes (KRASHEN, 1982), não só pela decodificação da mensagem, mas pela possibilidade de estabelecer similitudes e diferenças entre as duas línguas. No processo de compreensão o leitor é ativo (HODGES, NOBRE, 2012), isso porque trabalha no desenvolvimento de estratégias cognitivas e metacognitivas. Cabe lembrar que, nos níveis iniciais, deve-se trabalhar em unidades menores, por exemplo, ao nível das orações.

\section{"Feia demais"/‘"Demasiado fea”, de Nelson Rodrigues, apreciação crítica e alternativas pedagógicas}

$\mathrm{Na}$ origem desse trabalho está a ideia de se realizar uma série de atividades que possa dar conta de outras porções da produção do autor brasileiro, em português, acompanhadas com o trabalho textual ao redor de um dos seus contos, em tradução ao espanhol. O texto em consideração, "Feia demais", é um dos contos de A vida como ela é, livro que recolhe algumas das colunas que Nelson Rodrigues escrevera entre 1951 e 1961. O trânsito das colunas do jornal Última hora ao livro pode ser objeto de reflexões valiosas por parte dos estudantes: desde as repetições nos tipos de personagens até os modos de edição. Especialmente, trazer para sala de aula as crônicas e os contos, aquela parte da obra rodriguiana que não é canônica, é mostrar a multiplicidade de um autor que personifica um modo particular de ser escritor. Por outro lado, as temáticas que viraram uma marca registrada de Rodrigues continuam a ser populares entre o público, dado o seu interesse na natureza humana e nas relações complexas entre o desejo e a moral.

Os contos/crônicas de A vida como ela é caracterizam-se por certas recorrências de viés argumental: questões de índole familiar, problemas entre os casais, infidelidade e desamor por parte de um dos amantes. A estrutura também mantém semelhanças: início, empecilho e resolução. Por outro lado, o conto está escrito com um léxico que guarda proximidade nas duas línguas. 
"Feia demais" apresenta uma histórica trágica entre um homem apaixonado por uma mulher que, como o título mesmo informa, não é considerada bonita nem atraente por parte de ninguém. Antes mesmo de adentrar a leitura do conto, logo em seu título, destaca-se a posição marcante do advérbio acentuando esse caráter hediondo da figura física dela, quase mimetizando o fim trágico de algum que não é feia, apenas, é feia demais. Ao professor, será produtivo reforçar essa força acentuadora de uma palavra invariável que se presta a acentuar sentidos, no caso, aumentar a gradação de fealdade de uma das personagens.

O conto começa com uma cena que revela a percepção da família do noivo tem da futura esposa. Num emaranhado de ciúme, infidelidade, autoconsciência, traição e punição, o enredo decorre num misto entre vocabulário sedutor, ainda que marcado por expressões, hoje, em desuso, mas que podem render uma bela discussão em torno de diferenças vocabulares. Recomenda-se ao professor entregar só a primeira parte do conto, um diálogo que introduz a situação e alguns dos personagens.

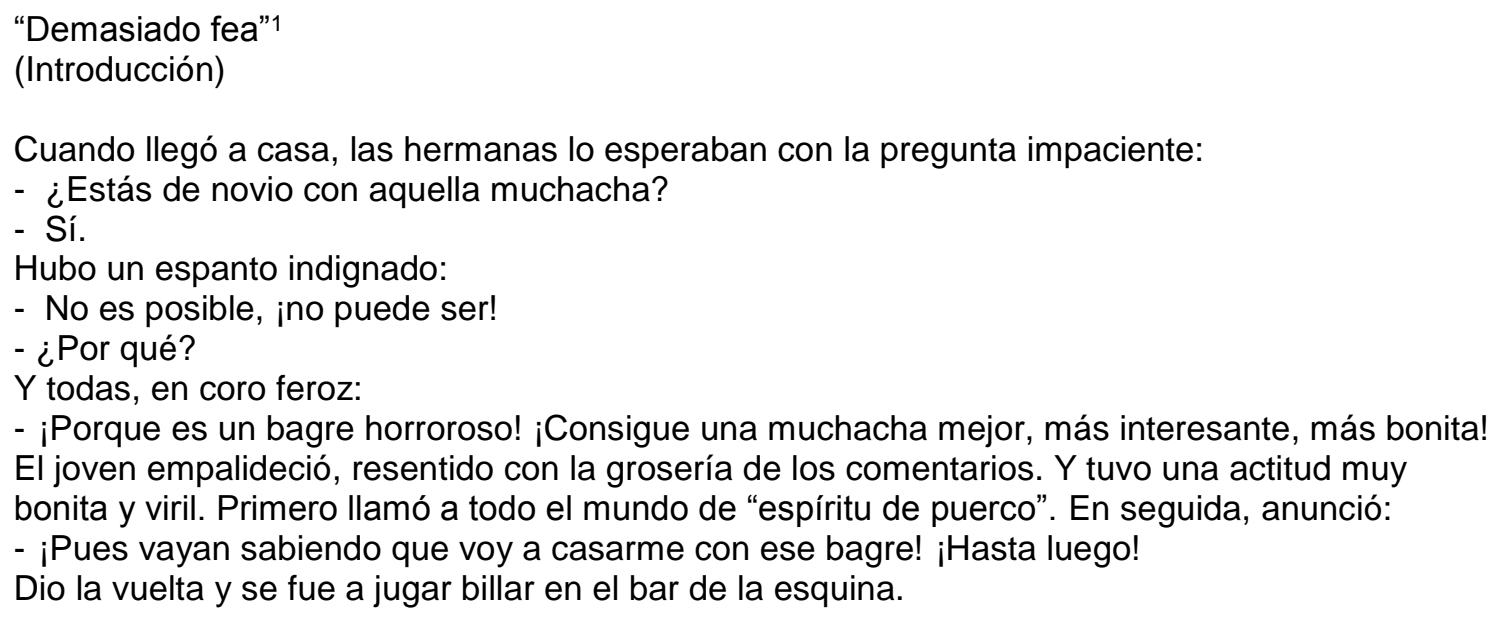

No caso de estudantes com um nível entre básico e intermediário, o texto não oferece grandes dificuldades. A maior parte do léxico, quando não for quase transparente pela proximidade entre as línguas, poderá ser inferido pelo contexto.

\footnotetext{
${ }^{1}$ Os trechos da crônica "Feia demais", utilizados nesse trabalho, foram traduzidos pelos autores, com o propósito específico da sua utilização nesse texto. As outras crônicas do livro A vida como ela é encontram-se em La vida tal cual es (2014). A crônica em sua versão em português consta na edição apontada na bibliografia.
} 
Não sendo um problema maior, a compreensão da mensagem deixa lugar para a reflexão em termos de pontuação: por exemplo, a diferença nos pontos de interrogação e exclamação que no espanhol devem ir no começo e no final das frases. Deve se destacar ainda o uso da expressão bagre ${ }^{2}$, coloquial, e de uso no espanhol falado de Argentina, Cuba, Equador, El Salvador e Uruguai. Vale a pena sempre chamar a atenção para os verbos, tanto regulares, quanto irregulares, que o texto apresenta.

No caso das línguas que essa proposta contempla: português e espanhol, a proximidade entre elas pode impactar tanto de forma positiva, quanto negativa 0 processo de aprendizagem. É preciso, consequentemente, usar todas as ferramentas para que os estudantes possam encarar a dita contiguidade do modo mais efetivo. Dito em outras palavras, o professor precisa encorajá-los para que esses se sintam dispostos no momento da produção, mas também para que estejam em alerta e percebam as diferenças. Nesse horizonte, a tradução é uma das esferas em que essa proximidade pode revelar as maiores dificuldades.

Depois de esgotar suas possibilidades no Método de Gramática e Tradução e após sofrer uma quase censura nas aulas no Método Comunicativo, o uso didático da tradução tem sido robustecido. Os avanços na didática das línguas e nos estudos tradutórios permitem uma rearticulação do seu uso na sala de aula. A prática tradutória coopera no aprimoramento tanto da língua estrangeira, quanto da primeira língua, isso pela compreensão profunda que demanda traduzir (PONTES, FREITAS, 2017).

Tem sido muitas as críticas para o uso da tradução: que ela pode produzir transferências, evitar os estudantes de pensar diretamente na língua estrangeira e que esse tempo pode se destinar para 0 ensino de outras habilidades (MALMKJÆER,1998). No entanto, hoje encontram-se diversas pesquisas que defendem os benefícios de certo tipo de tradução na aula, os quais irão depender da clareza dos objetivos com que essa prática for apresentada.

Os usos da tradução são variados, como enumera De Arriba García (1996): tradução pedagógica (com objetivo didático e público restringido), explicativa (usada

\footnotetext{
${ }^{2}$ A palavra faz parte da expressão "cabeça de bagre", usada em algumas zonas do Brasil para se referir a alguém muito feio também.
} 
por professores para explicar uma palavra), interiorizada (estratégia por parte do leitor ao encontrar novo vocabulário). No mesmo artigo, "Introducción a la traducción pedagógica", a pesquisadora destaca as dificuldades de um enfoque que use a tradução apenas para comprovar a compreensão dos aprendizes.

Entende-se, assim, que é preciso ampliar o leque de objetivos em relação à prática da tradução na aula: refletir sobre a atividade tradutória, reparar nas relações de equivalência, considerar as divergências entre as línguas, sobretudo, abrir o espaço para uma tradução que vincule o ato criativo. A tradução pedagógica pode ir da Língua Materna à Língua Estrangeira ou vice-versa. Nesse caso, a proposta vai do espanhol para o português, para privilegiar mesmo a parte criativa na $L 1$, assim os educandos podem se sentir mais à vontade na hora da criação, por terem mais recursos linguísticos à disposição.

Amparo Hurtado Albir (1993) define três fases no processo tradutor: compreensão, desverbalização e reexpressão. Essa última parte, a reexpressão, corresponde à transmissão do sentido do texto original na própria língua. No andamento dessa reexpressão, estudantes e professores devem ter em mente os muitos objetivos que podem ser alcançados nessa etapa: aperfeiçoamento da L1 por meio da paráfrase, a ampliação do vocabulário, a prática de estruturas gramaticais, a reflexão nas questões estéticas.

Raffaella Odicino (2015) recomenda, no caso de línguas afins, uma cuidadosa seleção dos textos que leve à capitalização das aproximações entre as línguas, e uma elaboração consciente dos comentários contrastivos nos níveis linguístico e extralinguístico.

A recomendação seguinte é que o professor, como mediador, incentive nos estudantes a traduzirem para o português do texto que já leram e compreenderam em espanhol. Nesse sentido, eles vão ter a liberdade de re-criar o texto. Entendida a mensagem por parte deles, resolvidas quaisquer dúvidas que puderem existir sobre vocabulário, eles terão de criar a sua própria versão com o aproveitamento da liberdade e conhecimento que sentem se tratando da Língua ${ }^{3}$.

\footnotetext{
3 Temos usado o termo Língua1 para nos referir ao Português, provavelmente a Língua Comum na sala de aula. Isso para evitar o conceito de Língua Materna que abre a possibilidade para pensar a diversidade de Línguas Maternas que podem se encontrar entre os aprendizes do país.
} 
A ideia é que o professor converse em sua aula sobre as diversas possibilidades linguísticas que os alunos podem introduzir na versão. Este se configura um bom momento para se deter nas noções de autoria, adaptação e versão. A sugestão para o educador é convidar os estudantes a avaliar o conceito de fidelidade textual dentro do território da criatividade e da liberdade de serem, eles mesmos, coautores de um texto do qual que se apropriam. Após essa fase, os estudantes terão a oportunidade de se encontrar com o texto fonte e, muito provavelmente, os dois textos irão diferir bastante:

\footnotetext{
"Feia demais"

Quando chegou em casa, as irmãs o esperavam com a pergunta sôfrega:

- Você está namorando aquela pequena?

- Estou.

Houve um espanto indignado:

- Não é possível, não pode ser!

- Por quê?

E todas, num coro feroz:

- Porque é um bucho horroroso! Arranja uma pequena melhor, mais interessante, bonitinha!

O rapaz empalideceu, ressentido com a grosseria dos comentários. E teve uma atitude muito bonita e viril. Primeiro chamou todo mundo de "espírito de porco". Em seguida, anunciou:

- Pois fiquem sabendo que eu vou me casar com esse bucho! Té logo!

Virou as costas e foi jogar sinuca no boteco da esquina.

(RODRIGUES, 1992, p. 133)
}

No âmbito da insistência sobre as diversas possibilidades de atuação advindas de uma postura curiosa e tradutória, vale lembrar as palavras do Paulo Rónai: "[...] se a crônica possui alguma característica substancial, é precisamente a sua intraduzibilidade" (2009, p. 180). O reconhecido tradutor referia-se ao vínculo profundo entre o texto e a realidade social e linguística do ambiente em que ela foi produzida. Como conto ou crônica, "Feia demais" expõe essa singularidade da expressão, que será refletida nas produções dos aprendizes na hora de traduzi-la.

Essa divergência entre o texto produzido pelos estudantes e o texto de Nelson Rodrigues amplia as possibilidades de trabalho. Não sendo um exercício que procure prescrever um jeito certo ou um jeito errado, a reflexão pode se debruçar nas escolhas que os autores dos diversos textos fizeram: ver como são resolvidos os diferentes embates textuais. 
Eis um efeito de desnaturalização que será de proveito para ver a Língua Materna com outros olhos. Assim, a Língua Portuguesa se apropria de um lugar novo e a Língua Espanhola também. "Sólo a partir del momento en que la lengua materna encuentra su sitio en el aula de lengua extranjera es posible la rehabilitación de la traducción pedagógica" (DE ARRIBA GARCÍA, 1996, p. 277).

\section{A proposta da Base Nacional Comum Curricular - Ensino Médio e o sequestro do espanhol como língua estrangeira moderna}

A proposta de Base Nacional Comum Curricular - Ensino Médio, documento homologado pela Portaria $\mathrm{n}^{\circ}$ 1.570, publicada no Diário Oficial da União de 21/12/2017, é fruto de intensas discussões de diversos setores. Em 2018, a discussão sobre a implementação oficial do documento mobilizará governo, setores da gestão educacional, educadores, pesquisadores, e sociedade civil, bem como sobre os resultados que esta norma, enquanto força de lei, regulará, ou não, as práticas cotidianas da vida na escola.

Paralelamente, além de se discutir a proposta a ser apreciada pelo Conselho Nacional de Educação, se o documento não possui a função de estabelecer o currículo, outro tópico que não se encontra pacificado, os interessados passarão, cada vez mais, a discutir currículos locais e práticas pedagógicas. Se o documento é um fim que garante o nível de formação básica dos educandos, é preciso, para não dizer, é obrigatório, agora, definir e pautar os caminhos que serão percorridos até este fim.

Quando se pensa no ensino de língua estrangeira, a proposta da base parece incluir uma alteração mais recente da Lei de Diretrizes e Bases da Educação, de 1996, que preconiza, sobre o sexto ano, do ensino fundamental, em sua última fase:

$\S 4^{\circ}$ Os currículos do ensino médio incluirão, obrigatoriamente, o estudo da língua inglesa e poderão ofertar outras línguas estrangeiras, em caráter optativo, preferencialmente o espanhol, de acordo com a disponibilidade de oferta, locais e horários definidos pelos sistemas de ensino. (BRASIL, 2017b)

A partir da leitura do parágrafo acima, ao caráter de obrigatoriedade da língua inglesa, sobrepondo a prerrogativa das unidades escolares de oferecerem a língua 
espanhola, o documento da base opta por sequestrar, ignorar, qualquer menção à língua espanhola. Tendo em vista o contexto social, cultural, geográfico, político, financeiro em que o Brasil participa atualmente, com diversas realidades hispanohablantes, a ausência do espanhol em toda a proposta do Ensino Médio causa estranheza.

O caráter estético também é apontado como um dos fatores que deverão pautar as práticas educacionais da educação básica brasileira, normatizadas pela proposta da base. Por educação básica, o documento entende três etapas formativas: a educação infantil, o ensino fundamental, e o ensino médio, etapa sobre a qual recai o nosso maior interesse nesse trabalho.

Mencionar a fruição estética implica avaliar uma manifestação artística, a literatura, por exemplo, como item defensável a priori pelo documento da base. É o aspecto estético que induz, logo no começo da leitura do documento, à procura de maiores especificidades sobre a normatização desse âmbito artístico, estético, nos termos da proposta, algo que a competência 3 , defende de maneira aberta, quando trata necessidade de se "[...] valorizar e fruir as diversas manifestações artísticas e culturais, das locais às mundiais, e também participar de práticas diversificadas da produção artístico-cultural” (BRASIL, 2017a, p. 9)

Baliza de um currículo comum em todo o território nacional, esse documento visa a garantia da aprendizagem de dez competências gerais. A noção de competência abarca a mobilização de conhecimentos, de maneira cidadã, no dia-adia e no mundo do trabalho.

Expressões como empatia, saúde emocional e respeito aos direitos humanos apontam para uma possibilidade de uma educação justa. Porém, quando se pensa no sequestro de expressões como "gênero", na conotação relacionada às diversas identidades e orientações sexuais, percebe-se que o documento patina em seus fundamentos de uma educação inclusiva, expressão, alardeada na própria norma ${ }^{4}$. A

\footnotetext{
${ }^{4}$ Quase ao final do documento, é possível encontrar uma passagem como: "Além disso, ao explorar variadas problemáticas próprias de Geografia e de História, prevê que os estudantes explorem diversos conhecimentos próprios das Ciências Humanas: noções de temporalidade, espacialidade e diversidade (de gênero, religião, tradições étnicas etc.)" (BRASIL, 2017 a, p. 123, grifo nosso). Se forem considerados todos os debates empenhados na exclusão dos termos ligados às populações LGBT+, formada por lésbicas, gays, bissexuais, travestis, transexuais e grupos diversos, movidos por grupos político-religiosos, a ocorrência soa como lapso.
} 
esse respeito, a exclusão do espanhol, no documento, esconde em seu falso pragmatismo, mais uma violência linguística e um contrassenso sobre um tópico que poderia ser visto como óbvio, ao se considerar a participação e o protagonismo do Brasil no Mercado Comum do Sul (Mercosul), por exemplo.

A ideia de uma base comum já consta no documento da Lei de Diretrizes e Bases da Educação (LDB), em redação de 2013. Naquela oportunidade, o documento anunciava:

"[...] os currículos da Educação Infantil, do Ensino Fundamental e do Ensino Médio devem ter base nacional comum, a ser complementada, em cada sistema de ensino e em cada estabelecimento escolar, por uma parte diversificada, exigida pelas características regionais e locais da sociedade, da cultura, da economia e dos educandos (BRASIL, 2013).

Essa lembrança da LBD alerta para o fato de que a proposta atual surge de uma cobrança histórica dessa base. Ainda que necessária, a formulação precisa, nessa discussão atual, ser apreciada pelos educadores e pela sociedade civil com vistas a possíveis reajustes futuros. Aos professores do componente Língua Espanhola, os desafios se agigantam tendo em vista que, num primeiro momento, não será possível, ao menos, discutir a regulação apresentada pelo documento em termos de elaboração de currículo.

\section{Considerações finais}

No horizonte de uma proposta que se utiliza da discussão de normas legais, o que poderia soar apenas prescritivo, se justifica mais na necessidade de o educador identificar, conhecer e analisar criticamente os documentos atinentes às suas práticas. A ideia de discutir as possibilidades de um texto literário, aqui, o conto/crônica de Nelson Rodrigues, "Feia demais', vincula-se aos pressupostos de que a literatura é, mais do que um bem de direito, uma manifestação humana capaz de assegurar a "[...] integridade espiritual" (CANDIDO, 2011, p.174) do sujeito. A imagem de um currículo vivo, realizado pelos atores educacionais, também se constitui na perspectiva da elaboração dessas propostas.

Com a implantação da base, recairá sobre as escolhas a necessidade de elaboração de currículos. Ao professor da educação básica, mais do que nunca, 
este é o momento de protagonizar a discussão, elaboração e implantação de práticas pedagógicas que irão reger sua rotina profissional.

Nesse cenário de discussão de marcos legais, encerra-se esse convite a integrar a tradução na aula, através de múltiplos enfoques e com diversos propósitos. É fundamental evitar erros que acabam por reduzir uma prática que em si tem muito potencial dentro do ensino. A falta de contextualização, quer dizer, a designação de textos para que sejam traduzidos sem nenhum conhecimento prévio do texto e do autor é um dos desacertos mais comuns. A recomendação para o professor é trabalhar junto com os estudantes quais são os objetivos específicos do exercício tradutório. Começar a prática sem ter essa perspectiva clara traz uma série de dificuldades, que podem acabar prejudicando o ambiente inteiro da aula.

Cabe reforçar a importância de se precisar com os estudantes o conceito de tradução que será trabalhado na aula. Sem receber nenhuma instrução acerca da metodologia que será usada, para os alunos, o exercício se torna uma tentativa de tradução literal com efeitos desmotivadores. Longe de pensar na tradução pedagógica como um método, a ideia é integrá-la como uma atividade que possa fazer parte das tentativas de se aproximar às línguas de um modo diferente e sempre significativo.

A construção dessa argumentação se dá no momento em que profissionais da educação estão diante da necessidade de leitura e avaliação de um documento que propõe "[...] a superação da fragmentação radicalmente disciplinar do conhecimento, o estímulo à sua aplicação na vida real, a importância do contexto para dar sentido ao que se aprende e o protagonismo do estudante em sua aprendizagem e na construção de seu projeto de vida (BRASIL, 2017, p. 15). Por isso mesmo, ainda que a Base Nacional Comum Curricular - Ensino Médio não apresente uma contribuição clara para o ensino de língua espanhola, este artigo poderá ser uma oportunidade para se discutir tais aspectos a respeito do ensino de língua e literatura no Ensino Médio.

\section{Referências bibliográficas}


AUSUBEL, D. The Psychology of Meaningful Verbal Learning: an introduction to school learning. New York: Grune \& Stratton, 1968.

BRASIL. PRESIDÊNCIA DA REPÚBLICA. Lei no 12.796, de 4 de abril de 2013. Disponível em: <http://www.planalto.gov.br/ccivil_03/_ato2011-2014/2013/lei//12796. htm>. Acesso em: 13 ago. 2018.

MINISTÉRIO DE EDUCAÇÃO. Base Nacional Comum Curricular Ensino Médio. 2017a. Disponível em: <http://basenacionalcomum.mec.gov.br/bnccensino-medio>. Acesso em: 13 ago. 2018.

. PRESIDÊNCIA DA REPÚBLICA. Lei № 13.415, de 16 de fevereiro de 2017b. Disponível em: <http://www2.camara.leg.br/legin/fed/lei/2017/lei-13415-16fevereiro-2017-784336-publicacaooriginal-152003-pl.html>. Acesso em: 13 ago. 2018.

CANDIDO, A. O direito à literatura. In: . Vários escritos. Ouro sobre Azul: Rio de Janeiro, p. 169-191, 2011

DE ARRIBA GARCÍA, C. Introducción a la traducción pedagógica. Lenguaje y Textos, Valéncia, v. 8, p. 269-283, 1996.

FISCHER, L. A. Inteligência com dor: Nelson Rodrigues ensaísta. Porto Alegre: Arquipélago Editorial, 2009.

FREIRE, P. A importância do ato de ler: em três artigos que se completam: São Paulo, 2011.

HODGES, L. V.; NOBRE, A. P. M. C. O uso de estratégias metacognitivas como suporte à compreensão textual. Revista Eletrônica de Educação, São Carlos, v. 6, p. 476-490, 2012.

HURTADO ALBIR, A. Un nuevo enfoque de la didáctica de la traducción. Metodología y diseño curricular. In: GAUCHOLA, R. ; MESTREIT, C. ; PLANET, M. $\mathrm{T}$. (Coord.)Les langues étrangeres dans l'Europe de l'Acte unique. Primer Congrés Internacional Sobre L'ensenyament Le Llengües Estrangeres., Barcelona: ICE-UAB, 1993.

MALMKJAER, K. (Ed.) Translation and Language Teaching: Language Teaching and Translation. Manchester: St. Jerome Publishing, 1998.

ODICINO, R. Traducción y creatividad en el proceso de enseñanza-aprendizaje de E/LE in MORIMOTO, Y.; LUCERO, M. V. P.; MARTÍNEZ, R. S. La enseñanza de ELE centrada en el alumno.. Madrid: Ed. Asociación para la Enseñanza del Español como Lengua Extranjera, 2015.

TES, V. O.; FREITAS, C. P. La traducción como una estrategia didáctica para la enseñanza de español como lengua extranjera. Transversal - Revista em Tradução, Fortaleza, v.3, p. 03-14, 2017. 
RODRIGUES, N. A vida como ela é. O homem fiel e outros contos. São Paulo: Companhia das Letras, 1992.

I.

. La vida tal cual es. Buenos Aires: Adriana Hidalgo Editora, 2014. Vol

La vida tal cual es. Buenos Aires: Adriana Hidalgo Editora, 2014. Vol

II.

RÓNAI, P. Encontros com o Brasil. Rio de Janeiro: Batel, 2010.

TERRELL, T. The role of grammar instruction in a communicative approach. The Modern Language Journal, [s.I.] v. 75, p. 52-63, 1991.

VANPATTEN, B. Input Processing and Grammar Instruction. Norwood: Ablex Publishing Corporation, 1996.

\section{Sobre os autores}

\section{Liliana Patricia Marlés Valencia}

Doutora em Letras pelo programa de Língua Espanhola e Literaturas Espanhola e Hispanoamericana da Universidade de São Paulo-USP (2017). Possui mestrado em Literatura Colombiana e Latino-americana pela Universidad del Valle (2009). É graduada em Línguas Modernas (2003) e em Espanhol e Literatura (2003), ambas pela Universidad del Quindío. Atualmente, desenvolve pesquisas ao redor da figura de autor nos escritores Nelson Rodrigues e Virgílio Piñera.

\section{Luciano de Jesus Gonçalves}

Professor de Português e suas Literaturas do Instituto Federal de Educação, Ciência e Tecnologia do Tocantins - IFTO. Atualmente, é doutorando no Programa de Pós-Graduação em Literatura Brasileira da Universidade de São Paulo - USP, onde desenvolve pesquisa sobre as relações intelectuais do escritor Samuel Rawet. Possui mestrado (2012) e graduação (2009) em Letras pela Universidade Federal de Mato Grosso do Sul - UFMS. 